\title{
A INFÂNCIA NO ENSINO FUNDAMENTAL OBRIGATÓRIO DE NOVE ANOS: O QUE DIZEM OS PROFESSORES DO PRIMEIRO ANO?
}

\author{
INFANCIA EN PRIMARIA OBLIGATORIA DE NUEVE AÑOS: ¿LO QUE DICEN \\ LOS PROFESORES DEL PRIMER AÑO?
}

\author{
CHILDHOOD IN FUNDAMENTAL FUNDAMENTAL TEACHING OF NINE \\ YEARS: WHAT DO THE TEACHERS SAY IN THE FIRST YEAR?
}

RESUMO: O conceito de infância está incontestavelmente ligado aos diálogos concernentes à educação das crianças. Sensíveis a esse contexto, a pesquisa intitulada: "A infância no ensino fundamental obrigatório de nove anos: o que dizem os professores do primeiro ano?" é resultado da inquietação acerca de como os professores que atuam juntos a estes sujeitos concretos, crianças, estão nomeando, enunciando e compreendendo a infância e a educação das crianças no contexto da educação de nove anos, mais especificamente no primeiro ano das séries iniciais do ensino fundamental. Assim, definimos como objetivo geral compreender os sentidos e significados que configuram os discursos veiculados entre os professores do primeiro ano dos anos iniciais do ensino fundamental, no que diz respeito à Infância. $\mathrm{O}$ aspecto definidor de nossa reflexão vale ressaltar, não é a idade cronológica, mas, o que esses discursos enunciam sobre a concepção de criança e infância. Nesse contexto, delimitamos como campo empírico Escolas Municipais da Cidade de Caruaru- PE, nas quais foram selecionadas dez professoras do primeiro ano dos anos iniciais do ensino fundamental. Para compreendermos os diversos sentidos e significados sobre infância apoiamo-nos em uma metodologia de enfoque hermenêutico. Como instrumento de coleta de dados utilizamos entrevistas semi-estruturadas. Em linhas gerais, as análises parciais dos discursos de tais professoras nos indicam que os sentidos e significados atribuídos à infância ainda estão muito ligados à concepção desenvolvimentista, relacionada a uma noção etapista e cronológica de criança e infância. No que diz respeito à proposta de educação para a infância os resultados revelam uma concepção de educação voltada, sobretudo, para a consolidação das metas do ensino fundamental. Além disso, identificamos também, uma preocupação excessiva das instituições educativas com a escolarização precoce que se concretiza na ênfase da leitura e a escrita formal como as principais finalidades e objetivos do $1^{\circ}$ ano do Ensino Fundamental, ressaltando o caráter propedêutico e compreendida como um momento fundamental de "investimento" no desenvolvimento da criança.

PALAVRAS-CHAVE: Infância. Professores. Ensino Fundamental de Nove Anos.

${ }^{1}$ Doutora em Educação. UFPE/CAA. Professora do curso de Pedagogia e do PPGEDUC. Email: cgislane@terra.com.br

2 Pedagoga. UFPE/CAA. 
RESUMEN: El concepto de infancia, sin duda, está ligado al diálogo sobre la educación de los niños. Sensible a este contexto, la investigación titulada: "Los niños en la enseñanza primaria obligatoria de nueve años: ¿lo que dicen los profesores del primer año?" es el resultado de la preocupación acerca de cómo los maestros que trabajan juntos a estos sujetos concretos, los niños, están designando, enunciando y comprendiendo la infancia y la educación de los niños en el contexto de la educación de nueve años, más específicamente en el primer año de los grados iniciales de la escuela primaria. Por lo tanto, definimos como el objetivo general comprender los sentidos y significados que dan forma a los discursos transmitidos entre los maestros del primer año de la enseñanza primaria, en relación a la infancia. El aspecto determinante de nuestra reflexión, cabe resaltar, no es la edad cronológica, pero lo que estos discursos enuncian sobre la concepción de la infancia y del niño. En este contexto, delimitamos como campo empírico escuelas municipales de la ciudad de Caruaru - PE, en que se seleccionaron diez maestras. Para comprender los diversos significados de la infancia, nos basamos en una metodología de enfoque hermenéutico. Como instrumento de recolección de datos, utilizamos entrevistas semiestructuradas. En general, el análisis parcial de los discursos de estas maestras nos indica que los significados atribuidos a la infancia están todavía muy unidos a la concepción desarrollista, relacionada a una noción etapista y cronológica de los niños y la infancia. Con respecto a la propuesta de educación para la infancia, los resultados revelan una educación con enfoque, sobre todo, en la consolidación de los objetivos de la escuela primaria. Además, se identificaron también una excesiva preocupación de las instituciones educativas con la educación precoz, que se realiza en el énfasis en la lectura y la escritura formal como los principales fines y objetivos del primer año de la escuela primaria,_resaltando el carácter propedéutico y entendida como un momento fundamental de "investimento" en el desarrollo infantil.

PALABRAS CLAVE: Infancia. Maestros. Escuela Primaria de Nueve Año.

ABSTRACT: The concept of childhood is undoubtedly linked to dialogues concerning the education of children. Sensitive to this context, the research entitled "Childhood in compulsory primary education of nine years: what do first-year teachers say?" Is a result of the concern about how teachers who work together with these concrete children are Naming, enunciating and understanding childhood and the education of children in the context of nine-year education, more specifically in the first year of the initial grades of elementary school. Thus, we define as a general objective to understand the meanings and meanings that configure the discourses conveyed among the teachers of the first year of the initial years of elementary school, in regard to Childhood. The defining aspect of our reflection is worth noting, it is not the chronological age, but, what these discourses enunciate about the conception of child and childhood. In this context, we defined as empirical field Municipal Schools of the City of Caruaru-PE, in which were selected ten teachers from the first year of the initial years of elementary school. In order to understand the various meanings and meanings about childhood, we rely on a methodology of hermeneutical approach. As a data collection instrument we used semi-structured interviews. In general terms, the partial analyzes of the discourses of such teachers indicate that the meanings and meanings attributed to childhood are still closely linked to the developmental concept, related to a statist and chronological notion of children and childhood. With regard to the proposal

RIAEE - Revista Ibero-Americana de Estudos em Educação, v.12, n.1, p. 479-495, 2017. 
of education for children, the results reveal a conception of education focused, above all, on the consolidation of the goals of elementary education. In addition, we also identified an excessive preoccupation of educational institutions with early schooling that takes the form of emphasis on reading and formal writing as the main purposes and objectives of the 1st year of elementary school, emphasizing the propaedeutic and understood as a moment Fundamental "investment" in child development.

KEYWORDS: Childhood. Teachers. Nine Years Old.

\section{Introdução}

Os conceitos que se atribuem à infância estão incontestavelmente ligados aos diálogos concernentes à educação das crianças. Assim, o processo educativo é elaborado de acordo com as verdades que acreditamos ser adequadas a elas. Conforme Larrosa (2006) "a verdade da infância é o modo como nossos saberes a dizem e, portanto, a própria infância fica reduzida àquilo que os nossos saberes podem objetivar e abarcar e aquilo que nossas práticas podem submeter, dominar e produzir. (p.194)

Nesse sentido reconhecer as crianças na sua especificidade, olhá-las e indagálas para além dos discursos produzidos sobre elas, nos parece ser um dos desafios hoje, quando pensamos ou praticamos a tarefa educativa. Um aspecto importante na estruturação dessa problemática diz respeito à recente aprovação do ensino de nove anos no Brasil, ação que gera importantes desafios para a área da educação da infância.

No campo da educação infantil, as reações a essa mudança proposta pela lei 11.274 de 2006 que antecipou a idade de ingresso no ensino fundamental obrigatório para os seis anos e ampliou a duração deste para nove anos, têm sido bastante diversas, e colocam, dentre outros aspectos, a preocupação com a escolarização, considerada precoce, das crianças de seis anos e até mesmo daquelas de cinco anos e com a adequação das propostas pedagógicas adotadas pelas escolas ao contingente de crianças mais novas que ingressam na primeira série, especialmente ao processo de afirmação da infância.

A implantação do primeiro ano do ensino fundamental foi pensada com as intenções de "oferecer maiores oportunidades de aprendizagem no período da escolarização obrigatória e assegurar que, ingressando mais cedo no sistema de ensino, as crianças prossigam nos estudos, alcançando maior nível de escolaridade." (BRASIL, 2004, p.14). Tal medida levanta diversos questionamentos, pois, mais do que o acesso é 
necessário repensar a qualidade da formação educacional dessas crianças, como elas estão sendo pensadas e acolhidas.

Sensíveis a esse contexto, a pesquisa intitulada: "A infância no ensino fundamental obrigatório de nove anos: o que dizem os professores do primeiro ano?" é resultado da inquietação acerca de como os professores que atuam juntos a estes sujeitos concretos, crianças, estão nomeando, enunciando e compreendendo a infância e a educação das crianças no contexto da educação de nove anos, mais especificamente no primeiro ano das séries iniciais do ensino fundamental.

Assim, definimos como objetivo geral compreender os sentidos e significados que configuram os discursos veiculados entre os professores do primeiro ano dos anos iniciais do ensino fundamental, no que diz respeito à infância. $\mathrm{O}$ aspecto definidor de nossa reflexão vale ressaltar, não é a idade cronológica, mas, o que esses discursos anunciam sobre a concepção de criança e infância.

Nesse contexto, delimitamos como campo empírico as escolas municipais da Cidade de Caruaru- PE, nas quais foram nomeadas nove professoras do primeiro ano do ensino fundamental. Para compreendermos os diversos sentidos e significados sobre infância apoiamo-nos em uma metodologia de enfoque hermenêutico. Como instrumento de coleta de dados utilizamos entrevistas semi-estruturadas. No que segue apresentamos uma aproximação analítica dos dados da pesquisa.

\section{Criança/Infância}

O sentido de infância muda de acordo com o contexto histórico, social, político e econômico de cada época. Varia ainda de região para região, de cidade para cidade, de cultura para cultura, ou até mesmo dentro de uma mesma família, existindo, por tanto, infâncias e não só uma infância. Dentre essa diversidade há algo em comum: é sempre de crianças que estamos a falar e é irredutível ao mundo dos adultos a sua identidade. (SARMENTO\&PINTO 1997).

De acordo com os estudos de Ariès (2006) existiram diversas fases quanto à evolução do sentimento de infância. Durante a Idade Média, não havia distinção entre adultos e crianças, eles compartilhavam os mesmos lugares, assuntos e trabalhos, também não havia preocupação moral ou educativa. Na sociedade medieval não havia 
divisão territorial e de atividades em função da idade dos indivíduos, não havia o sentimento de infância ou uma representação elaborada dessa fase da vida. (ARIÈS, 2006). Não significa dizer, no entanto, que as crianças não existiam, elas sempre existiram, só que, por muitos anos, o sentimento de infância não teve representatividade. A mortalidade infantil, nessa época, era alta e, mesmo assim, o sentimento de luto ou saudosismo era raro, pois em geral não se pensava em manter alguma lembrança ou retrato da criança falecida. A partir do século XIII as obras de arte começam a exibir a infância, em geral na forma do menino Jesus ou de anjos. Aos poucos, com o crescimento do sentimento em relação à criança, a infância passou também a ser representada nos retratos de família.

Segundo Postman (1999) a invenção da prensa Tipográfica também foi responsável por muitas mudanças culturais que acabaram por influenciar na ressignificação do termo infância. A expansão dos livros tornou necessária a aprendizagem e o domínio da leitura numa época em que poucos (adultos) sabiam ler. Como esta era uma marca da sociedade adulta, as crianças, para entrar no mundo adulto, deveriam aprender a ler, o que demandou a escolarização. Acreditava-se que elas não passavam de adultos não formados, que precisavam ser civilizados através da educação para poder chegar a adultez. Essa foi uma das primeiras separações entre o mundo dos adultos e o mundo das crianças, a capacidade de leitura.

Assim, no século XV foram criados vários colégios, a fim de educar para a formação moral e intelectual. Nessas instituições havia uma combinação de ternura com severidade. Era comum a falta de referência às idades escolares, pois, como afirma Ariès (2006) “[...] durante muito tempo a escola permaneceu indiferente à repartição e à distinção das idades, pois seu objetivo essencial não era a educação da infância." (p.124)

No século XVII alguns pensadores Renascentistas iniciaram discussões em torno da criança e da sua educação que acabaram por contribuir com a formação do pensamento moderno de infância. Duas concepções foram as que mais se destacaram na época, as de John Locke e as de Rousseau. Para Locke as crianças, ao nascer, eram como uma tábula rasa, onde poderia-se escrever o que se julgasse necessário para as crianças. A educação, nessa perspectiva, teria o papel de cuidar e formar os pequenos para serem adultos civilizados. Já Rousseau dá uma especial importância à preservação das crianças aos "segredos adultos", já que sob sua visão, elas seriam seres bons e 
puros, merecedoras de proteção e amor. Para ele a educação deveria preservar a inocência infantil.

Superando as diferenças entre as ideias utilitaristas de Locke e o romantismo de Rousseau, há uma interseção nas ideias desses pensadores: o reconhecimento da infância e da necessidade de práticas educativas pensadas para as crianças. Como observa Pinto (1997) "Em ambos os casos se detecta, de facto, o reconhecimento do caráter decisivo da atenção e da intervenção dos adultos no processo de formação das crianças" (p.41).

Com a Renascença notam-se novos rumos para o sentimento de infância, mas convém falar que essas mudanças fizeram parte de um processo muito lento, o qual se deu com maior intensidade nas classes mais abastadas. Em todo caso, elas foram muito importantes para o sentimento de infância na contemporaneidade.

No Brasil a discussão sobre o reconhecimento social da criança/infância é parte de um processo mais amplo e só começa a ganhar espaço, sobretudo, no decorrer do século XX. Sabe-se que no que se refere às conquistas referentes aos interesses específicos da criança ainda é um desafio. Tal condição, no mínimo, indica a necessidade de um conhecimento mais profundo seja dessa realidade seja da própria condição de ser criança. No que diz respeito ao contexto educacional brasileiro, o cenário não é outro. Ainda observamos um descompasso entre a organização do nosso sistema de educação e a valorização das dimensões infantis, além de problemas estruturais. Veremos adiante uma rápida discussão sobre as questões que surgem quanto à afirmação da infância no primeiro ano do ensino fundamental, ano estabelecido como o primeiro da escolaridade obrigatória.

\section{A infância no Ensino Fundamental de Nove Anos}

A discussão sobre a entrada das crianças de seis anos no Ensino Fundamental insere-se num contexto onde o tema infância nunca foi tão tratado. Partindo do pressuposto que as concepções sobre infância atravessam as reformas educacionais e têm influência direta na vida de crianças de todas as classes sociais, faz-se urgente e necessário repensar quais as representações infantis embasaram a ampliação do ensino fundamental, mais especificamente na implantação do primeiro ano. 
A ampliação do Ensino Fundamental tem seu marco legal com a aprovação da Lei $\mathrm{n}^{\circ} 11.274 / 2006$, que altera a LDB e torna obrigatória a matrícula das crianças aos seis anos de idade no primeiro ano. As principais intenções seriam de "oferecer maiores oportunidades de aprendizagem no período da escolarização obrigatória e assegurar que, ingressando mais cedo no sistema de ensino, as crianças prossigam nos estudos, alcançando maior nível de escolaridade (BRASIL, 2004, p.14)”. Tais objetivos provocam interrogações, pois, mais do que democratizar o acesso e a permanência dos alunos do Ensino Fundamental é preciso observar a qualidade dessa mudança na estrutura da educação básica, sobretudo no primeiro ano.

Essa qualidade diz respeito à estrutura espacial, aos currículos e programas escolares, ao tempo escolar, dentre outros aspectos que são organizados e priorizados de acordo com o que se julga ser necessário e adequado as crianças. No caso do primeiro ano, podemos dizer que, da maneira como foi organizado, a escolarização toma dimensão prioritária de alfabetização, onde nem sempre as possibilidades infantis são evidenciadas e os pensamentos potencializados. A lógica, na escola, continua sendo pensada por e para adultos. Nesse contexto, as crianças, principalmente aquelas que não vivenciaram a educação infantil, terão grandes chances de se frustrar logo no início de uma etapa a qual permanecerão (ou não) por muitos anos.

Talvez escutar a infância possa ser um caminho para outra escolarização possível. Afinal, os tempos são outros e os processos de escolarização não podem estar vinculados à manutenção de um modo conservador de estruturação pessoal e social. (BARBOSA e DELGADO, 2012, p.119)

Outro ponto a se destacar é a comum separação do ensino fundamental da educação infantil. As músicas, as brincadeiras, as conversas entre os pares, parecem ficar restritos a educação infantil. O controle dos diálogos e dos corpos das crianças torna-se marcante no Ensino Fundamental. Diante desse contexto Kramer, (2007) observa que a "Educação Infantil e Ensino Fundamental são indissociáveis: ambos envolvem conhecimentos e afetos, saberes e valores; cuidados e atenção; seriedade e riso.” (p.20) O acolhimento não deveria mudar, pois, em todos os casos temos sempre crianças. E elas necessitam de uma proposta que as contemplem também em suas diferenças. 
Para isso é preciso garantir que as crianças sejam atendidas nas suas necessidades (a de aprender e a de brincar), que o trabalho seja planejado acompanhado por adultos na educação infantil e no ensino fundamental e que saibamos, em ambos, ver, entender e lidar com as crianças como crianças e não apenas como estudantes. (KRAMER ,2007, p.20)

Podemos afirmar, então, que a educação da infância no primeiro ano do Ensino Fundamental requer ampla reflexão. Esse parece ser o momento favorável para revermos também as nossas posições como educadores da infância. Tal como coloca Nascimento (2007):

Refletir sobre a infância em sua pluralidade dentro da escola é, também, pensar nos espaços que tem sido destinados para que a criança possa viver esse tempo de vida com todos os direitos e deveres assegurados.[...] Está posto aí um novo desafio: utilizar essa ocasião para revisitar velhos conceitos e colocar em cheque algumas convicções. (p.28)

Esse parece ser o principal desafio. Nos arriscarmos mais, nos despirmos de nossas velhas certezas, abrirmos nosso tempo ao tempo das crianças, conhecê-las, respeitá-las. No que segue iremos discutir mais sobre esse novo olhar sobre a infância, concatenado a educação.

\section{Da Afirmação da Infância}

Muito se fala sobre a infância. Contudo, apesar do avanço dos estudos sobre o tema, não é incomum a dificuldade em lidar com essa dimensão, sobretudo nas salas de aula. Escutar o que as crianças têm a dizer, permitir que se expressem, que aprendam brincando (inclusive livremente), que afirmem sua alteridade, requer constante reflexão sobre nossos papeis como educadores. Esta trata-se de uma tarefa desafiadora pois a criança é um ser que foge a nossa lógica, é um outro que transgride nossas pretensões.

Isso é a experiência da criança como um outro: o encontro de uma verdade que não aceita a medida do nosso saber, com uma demanda de iniciativa que não aceita a medida a medida do nosso saber, e com uma exigência de hospitalidade que não aceita a medida de nossa casa. (LARROSA, 2006, p.187) 
Esse modo de enxergar as crianças busca desdobrar potências impensadas na infância. Não é o caso de infantilizar-se ou deixá-las a própria sorte e sim de valorizar o poder de renovação que está contido na infância: "O nome de uma faculdade chamada criação, transformação, revolução, isso é a infância” (KOHAN, 2010, p.47).

Apesar das mudanças e do processo de ressignificação em relação à concepção de infância, a escola das crianças ainda está vinculada à ideia de um vir a ser adulto, implicada a uma noção de infância "capturável, numerável, tecnicamente explicada pelo conjunto de saberes" (KOHAN, 2003). Nós educadores ainda temos muito presentes essas características em nossas práticas. Por vezes colocamos as crianças em nossas projeções, como se já soubéssemos do que elas necessitam ou o que querem.

Observamos, então, que em nossos espaços educacionais há uma grande preocupação com o ensinar para o futuro, com a obediência e com o controle corporal e das vozes das crianças e desconhecem, em geral, uma maneira contemporânea de entender as crianças: como sujeitos sociais. "Nesse sentido, a infância é formada por sujeitos ativos e competentes, com características diferentes dos adultos" (NASCIMENTO, 2011, p.41)

Uma reflexão mais filosófica da infância sinaliza que é hora de aprendermos um pouco mais com as crianças, valorizando a infância minoritária, a qual para Kohan (2010)

É a infância como experiência, como acontecimento, como ruptura da história, como revolução, como resistência e como criação. [...] É a infância como intensidade, um situar-se intensivo no mundo, um sair sempre do "seu" lugar e se situar em outros lugares, desconhecidos, inusitados, inesperados (p.63)

Frente a essa realidade da educação, procuramos entender como os professores da cidade de Caruaru estão pensando as crianças que ingressam no primeiro ano do Ensino Fundamental, e como suas práticas relacionam-se com a afirmação da infância.

\section{Problematizando os sentidos e significados atribuídos pelos professores à infância nos anos iniciais do ensino fundamental}

Em sua totalidade o trabalho em questão abrangeu cinco escolas da rede municipal de Caruaru e que estão situadas em bairros periféricos. Em cada uma das 
escolas foram entrevistadas professoras atuantes nas salas dos primeiros anos do ensino fundamental, resultando no total de nove professoras.

Tais instituições, no geral, são de grande porte, mas com uma estrutura não muito adequadas para a educação da infância. Quanto aos perfis de nossos sujeitos, a maior parte possui mais de 10 anos de carreira, enquanto que apenas duas delas têm entre quatro e cinco anos de profissão. Indagadas sobre os motivos da escolha do campo de atuação algumas professoras relataram ter escolhido porque "amam alfabetizar". Tal fato já evidencia o quanto os sujeitos entrevistados estão articulados com a ideia de uma educação de caráter meramente alfabetizante. A seguir veremos os principais enunciados e concepções veiculados entre os professores sobre a infância no primeiro ano do ensino fundamental.

\section{Criança e Infância: o que dizem os professores?}

O termo infância passou por diversas conceitualizações as quais variavam de acordo com o contexto cultural, social, financeiro, demográfico e cultural de cada época, o que garante ao termo um caráter histórico. Por conseguinte, esses fatores acabaram por influenciar o tratamento com a criança tanto no seio familiar quanto na escola. É levando em consideração esta relação entre a concepção de infância e a educação de crianças que resolvemos inicialmente, em nossas entrevistas, investigar como as professoras do primeiro ano do ensino fundamental compreendiam esses sujeitos no contexto de suas práticas.

A maior parte das professoras entrevistadas diz conceber a infância como um momento onde a criança tem que ser livre, brincar e descobrir. Porém, também encontramos em algumas falas uma maneira bastante romântica de entender a infância: como preparação para o futuro. Tal como expressam as falas das professoras 1 e 7: “Ave Maria, é tudo. Uma infância é teu futuro, é o que você será no futuro.” (Profa. 1), "Infância é a base de tudo, é amor, é carinho, é atenção. É a base. Se você teve uma infância boa, você vai ter uma boa formação. ” (Profa. 7).

Ao colocar a infância como uma categoria que deve ser preparada para o futuro, sempre guiada pela lógica adulta, não se reconhece, por tanto, o valor dado a criança enquanto sujeito na sociedade, enquanto outro. "É um outro porque sempre é outra 
coisa diferente do que podemos antecipar, porque está além do que sabemos, ou do que queremos ou do que esperamos.(LARROSA, 2006, p.187)

Mesmo após alguns séculos do surgimento do sentimento de infância, de várias conquistas legais e pesquisas acadêmicas voltadas ao tema, há algo que parece não mudar ao longo dos tempos: o fato de que nem todas as crianças conseguem vivenciar a infância. Entre os professores entrevistados a ideia mais frequiente é a de que a vivência da infância está diretamente ligada às condições econômicas e culturais. Nesse caso, todas foram unânimes em concordar que o fato de ser criança não significa ter infância.

Não porque tem muitas crianças que não passam pela fase do brincar, do socializar... tem que trabalhar, ajudar os pais ou os pais não colocam na escola...tem alunos aqui que nunca foram a escola.(Profa.6)

Entendemos, portanto que a vivência da infância encontra barreiras nas condições sociais, assim, muitas crianças tem suas infâncias tolhidas. Somado a esse fato, as decisões políticas e as tendências culturais também apontam para que as crianças tornem-se adolescentes, precoces, competitivos, erotizados, cada vez mais cedo. (BARBOSA E CRAIDY, 2012)

Embora os professores discordem da existência de uma infância como uma condição e experiência comum a todas as crianças, todas vão nomear o brincar como uma de suas principais marcas. Dessa forma o brincar foi compreendido pelos professores como uma das atividades que melhor expressa a manifestação infantil, tal como mostra o relato abaixo:

O principal eu acho é o brincar. É onde a criança mais se desenvolve nesse período, na infância (Profa.06).

Brincar, conversar, a criança necessita muito de conversa. Então, quanto mais você conversar com a criança, melhor é para o desempenho dela, para o desenvolvimento dela. É o que é próprio mesmo da criança. É o brincar, o conversar, o imitar, que elas gostam muito (Profa. 07)

O brincar nos parece ser uma característica reconhecida universalmente no que diz respeito às crianças, no entanto, a valorização dessa particularidade ainda encontra pouco espaço nas instituições educacionais. Ao ingressarem no primeiro ano do ensino fundamental esse fato se intensifica e o mundo infantil parece se distanciar cada vez mais da criança. Além disso, identificamos também o brincar tido como um meio de 
desenvolver habilidades, que auxilia a criança, ou seja, concebido com uma visão utilitarista.

Tais concepções revelam a necessidade de quebrarmos as imagens tanto românticas como adultocêntricas sobre as crianças e sobre as infâncias. Mais do que qualquer outra coisa os relatos na sua totalidade revelam a necessidade dos professores pensarem mais sobre as crianças e a infância a partir delas mesmas e não dos adultos.

Certas de que a educação das crianças ao entrarem no ensino fundamental com vistas à valorização da criança não é uma tarefa fácil, nos interessou saber como essas professoras tem tratado as dimensões da infância nessa nova configuração do ensino fundamental.

\section{A Infância no Primeiro Ano dos Anos Iniciais do Ensino Fundamental: afirmação e resistência}

Uma das questões, a qual daremos ênfase nesse ponto da nossa análise, discute como a educação vem considerando a infância nas suas possibilidades com foco no primeiro ano.

A aprovação da Lei $n^{\circ} 11.274$ de 6 de fevereiro de 2006 que altera a LDB, amplia o Ensino Fundamental para nove anos de duração e torna obrigatória a matrícula de crianças de seis anos de idade é alvo de diversas críticas, pois deixa em aberto um leque de questionamentos, tornando confusas as escolas, as famílias e, sobretudo, as crianças.

É necessário entender que a entrada na escola, já no ensino fundamental, é um momento delicado, pois a criança entra em uma rotina cheia de obrigações e onde diferentes habilidades lhes serão cobradas, terá ainda que se acostumar com a divisão da atenção e do espaço com diferentes crianças, tudo isso longe da família. Essa adaptação à escola torna-se ainda mais tensa se pensarmos que o ensino fundamental demanda conhecimentos e habilidades, as quais, em geral, as crianças que não vivenciaram a educação infantil não desenvolveram.

Assim, as crianças terão pouco tempo para se acostumar com a rotina da escola para logo se encaixarem no tempo determinado pelos adultos; o modelo de ensino escolar tradicional. Nessa perspectiva entendemos ser necessário apreender como as professoras estão acolhendo essas crianças; como as dimensões da infância no primeiro 
ano do ensino fundamental estão sendo tratadas. Sobre essa questão a professora abaixo vai nos dizer que essa é uma das questões fortes no seu trabalho.

Assim, eu trabalho muito assim com eles as datas comemorativas, não deixo passar. Sempre falo com eles que a gente ta na sala dos meninos maiorzinhos, pulando uma casinha a mais. Sempre a gente não pode esquecer o que a gente tem que fazer, como trabalhar, dividir, multiplicar. (Profa. 5)

A fala dessa professora exemplifica bem a postura da maior parte de nossas entrevistadas: a preocupação com os conteúdos. A criança é valorizada, sobretudo como o aluno que deve ser preparado para as séries futuras. Diante das cobranças do próprio sistema de ensino, a valorização das potencialidades infantis sede lugar as práticas escolarizantes:

Eu tento amenizar o máximo possível, assim, pra não sobrecarregar muito eles, eu tento assim com dinâmicas: boca de forno! Brincando, vamos fazer mímica, vamos fazer ginástica, pra não tornar aquela aula tão chata e cansativa. (...) E até porque a gente ta num programa que é também é um pouco...muita leitura, leitura, leitura, treinar leitura, treinar os fonemas, as vozes. É o IAB, o Alfa e Beto. Aí requer muita atenção e muito tempo, aí eles ficam muito estressados, entendeu? (Profa. 2)

No geral, percebemos que as próprias professoras sabem que o primeiro ano demanda muitos cuidados com a adaptação da criança e que brincadeiras e jogos podem ajudar, no entanto, essas atividades vão perdendo cada vez mais espaço para as os componentes curriculares especialmente de português e matemática.

A partir dessas falas podemos entender que de fato apenas definir a idade para o ingresso no ensino obrigatório não é a solução para a melhoria do nosso sistema de educação, uma vez que garantir o acesso não significa que as crianças terão qualidade na aprendizagem. No caso das escolas as quais escolhemos como campo empírico, que atendem crianças de renda baixa e onde muitas não passaram pela pré-escola, essas questões se ampliam. Se essa reorganização do ensino fundamental obrigatório não foi pensado com vistas à valorização do que é próprio das crianças, quando se fala de crianças das classes mais pobres o cenário é ainda mais preocupante.

Infância, o ensinar e o aprender no primeiro ano do ensino fundamental: o que dizem e pensam os professores? 
Tal como já foi abordado, o ensino fundamental de nove anos constitui-se em uma proposta que precisa ser cuidadosamente e constantemente (re) pensada, pois, além do acesso, também temos que considerar a qualidade do processo formativo.

As crianças de seis anos, mesmo que ingressem no primeiro ano sem ter passado pela pré escola certamente não ingressarão sem história, como uma folha em branco. As suas vivências de mundo, seus discursos, suas culturas, as suas famílias, do que gostam de brincar, por exemplo, já indicam aspectos sobre a vida, as necessidades e habilidades dessas crianças. Tais informações, portanto, deveriam ser o pano de fundo para se desenvolver a aprendizagem, pois, como coloca Redin (2012) "se forem "ouvidas e sentidas, com toda a sua inteireza, pelos adultos que com elas compartilham espaços de aprendizagem, transformarão, aos poucos, suas experiências em atos ricos de significados." ( p.103).

No entanto, as falas das nossas entrevistadas como mostra o relato abaixo, ainda é um desafio lançar um olhar mais receptivo às experiências das crianças: "O objetivo principal da gente é que ele aprenda a ler, né? Em segundo lugar é atender as normas da escola. A gente vai adequando a isso." (Profa.3) ou ainda como mostra a outra professora no relato a seguir:

Em primeiro momento eu priorizei a socialização e, assim, como é o objetivo de um primeiro ano, ele tá como uma alfabetização, que é pra você alfabetizar então a gente tenta desenvolver isso. Uma alfabetização não propriamente dita que eles não vão sair lendo fluentemente, mas tendo uma noção pra chegar ao segundo ano, que é a antiga primeira série, tendo uma noção. (Profa.6)

Nessa mesma perspectiva, os conteúdos que têm sido priorizados por esse grupo de professoras são os que estão mais relacionados ao ensinar a ler e escrever: "O conteúdos, realmente, como a gente trabalha com um projeto, a gente tem que dar conta dele né? Tem que trabalhar os fonemas, os grafemas, as famílias, etc., do programa Alfa e Beto.” (Profa.6)

Ao serem questionadas se os jogos e brincadeiras são importantes para as turmas nas quais atuam, todas as professoras foram unânimes em destacar a importância, sobretudo, didática dessas atividades: "Para a coordenação" (Profa.1), "Para facilitar o ensino de Português e Matemática"(Profa.2), "Para trabalhar o coletivo"(Profa.3), "Para se desenvolverem"(Profa.4), "Para desenvolverem o raciocínio e as habilidades"(Profa.5), "Para extravasar a energia deles"(Profa.6) Embora o brincar 
represente algo importante para as professoras, percebemos que há uma grande dificuldade para reservar um tempo na rotina escolar onde as crianças possam brincar livremente, como pode ser evidenciado na fala abaixo:

\begin{abstract}
Muito pouco. Quase se restringe ao recreio, ou quando eles terminam as tarefas que eu deixo que eles brinquem e brinquem com a massinha que é levada por mim mesma, não é a escola que oferece. Eu levo massinha, bolas de gude, joguinhos. E a gente é muito cobrada porque quando as crianças estão brincando é como se não estivessem fazendo nada, mas, a gente sabe que ela está fazendo alguma coisa. Mas, quem chega pergunta o porque que elas estão brincando. A gente vê que já são tantas atribuições que o primeiro ano já tem que acaba restringindo esse momento. (Profa.9)
\end{abstract}

É visível que devido às cobranças por resultados, trabalhar as múltiplas linguagens é uma tarefa considerada difícil no processo formativo infantil, pois, as atividades escolarizantes acabam vencendo qualquer iniciativa mais aprendente do mundo dessas crianças. Tratando-se do primeiro ano do ensino fundamental, a lógica adulta parece ganhar ainda mais força, visto que é consensual que estas crianças estão numa série onde a alfabetização deve ser priorizada. "O tempo do adulto é o tempo do relógio, o tempo da criança é quanto dura o prazer do que está fazendo, é de uma outra ordem, que sempre está em confronto com o mundo adulto." (MORETTI E SILVA, 2011, p.45)

\title{
Considerações finais
}

Em linhas gerais, as análises parciais dos discursos de tais professoras nos indicam que os sentidos e significados atribuídos à infância, no primeiro ano do ensino fundamental, ainda estão muito ligados à concepção desenvolvimentista, relacionada a uma noção etapista e cronológica de criança e infância.

No que diz respeito à proposta de educação para a infância os resultados revelam uma concepção de educação voltada, sobretudo, para a consolidação das metas do ensino fundamental. Podemos dizer que as propostas parecem ainda se fecharem em uma visão adulta do que seriam as necessidades das crianças.

Além disso, identificamos também, uma preocupação excessiva das instituições educativas com a escolarização precoce que se concretiza na ênfase da leitura e a escrita 
formal como as principais finalidades e objetivos do $1^{\circ}$ ano do Ensino Fundamental, ressaltando o caráter propedêutico e compreendida como um momento fundamental de "investimento" no desenvolvimento da criança.

\section{Referências}

ARIÉS, Philippe. História Social da Criança e da Família. Rio de Janeiro: LTC, 2006.

BARBOSA, M. C., DELGADO, A. C.C. (orgs.) A infância no ensino fundamental de 9 anos. - Porto Alegre: Penso,2012.

BARBOSA, M. C. S., CRAIDY, C. M. Ingresso obrigatório no Ensino Fundamental aos 6 anos. Falsa solução para um falso problema In: BARBOSA, M. C., DELGADO, A. C.C. (org.) A infância no ensino fundamental de 9 anos. - Porto Alegre: Penso,2012.

BRASIL. Ministério da Educação. Secretaria de Educação Básica. Ensino Fundamental de Nove Anos - Orientações Gerais. Julho de 2004.

KOHAN, Walter O. (org.) Lugares da infância: filosofia. Rio de Janeiro, DP\&A, 2004. Reimpressão: Rio de Janeiro: Lamparina, 2010.

KOHAN, Walter O. Infância. Entre Educação e Filosofia. Belo Horizonte: Autêntica: 2003.

KRAMER, Sonia. A infância e sua singularidade. In: BRASIL. Ministério da Educação. Secretaria de Educação Básica. Ensino Fundamental de nove anos: orientações para a inclusão da criança de seis anos de idade, 2007

LARROSA, Jorge. Pedagogia Profana: danças, piruetas e mascaradas. 4. Ed., Belo Horizonte: Autêntica, 2006.

MORETTI, N. M., SILVA, N. A. da. Brincar na educação infantil. Transgressões e rebeldias. In: FARIA (org.) Culturas Infantis em creches e pré-escolas:

estágio e pesquisa. Campinas, SP: Autores Associados, 1ª Ed., 2011, 171p

NASCIMENTO, M. L. B. P. Reconhecimento da Sociologia da infância como área de conhecimento e campo de pesquisa. In: FARIA, A. L G. e FINCO, D. (orgs.) Sociologia da infância no Brasil. - Campinas, SP: Autores Associados, 2011.

NASCIMENTO, A. M. A infância na escola e na vida: uma relação fundamental. In: BRASIL. Ministério da Educação. Secretaria de Educação Básica. Ensino Fundamental de nove anos: orientações para a inclusão da criança de seis anos de idade, 2007 
PINTO, M. A infância como construção social. In: SARMENTO, M. J. (Coords.). As crianças: Contextos e Identidades. Braga, Portugal: Centro de Estudos da Criança Universidade do Minho, 1997.

POSTMAN, Neil. O Desaparecimento da Infância. Rio de Janeiro: Graphia, 1999.

REDIN, M.M. Múltiplas Linguagens na Infância. Um mundo cheio de "girabelhinhas". In: BARBOSA, M. C., DELGADO, A. C.C. (org.) A infância no ensino fundamental de 9 anos. - Porto Alegre: Penso,2012.

\section{Como citar este artigo:}

SALLES, Conceição G. Nóbrega L. de.; SERCUNDES, Isabelle. A infância no ensino fundamental obrigatório de nove anos: o que dizem os professores do primeiro ano? Revista Ibero-Americana de Estudos em Educação, Araraquara, v.12, n.1, p. 479495, 2017. Disponível em: <http://dx.doi.org/10.21723/riaee.v12.n1.7597>. E-ISSN: 1982-5587.

Data de submissão: out/2015

Aprovação final: dez/2016 